\title{
USE OF TECHNOLOGY FOR SUPPORTING AND DEVELOPING THE NATIONAL OPEN UNIVERSITY OF NIGERIA
}

\author{
OGIDAN, Rotimi PhD \\ National Open University of Nigeria \\ email: jogidan@nou.edu.ng, \\ ogidanrotimi@yahoo.co.uk
}

\begin{abstract}
In a country with three million applicants every year, there is very high demand for university education. Conventional universities cannot cope with admission problems because they lack manpower and infrastructural facilities. One of the ways of solving this problem was the establishment of the National Open University of Nigeria. Coping with large population of students is not a problem in the National Open University of Nigeria because of the extensive use of information and communication technology (ICT) to reach learners even in remote locations. However, adequate measures need to be initiated so that more qualified technical staff are employed and basic infrastructure is put in place to cope with these challenges. Besides, it is suggested that students should be compelled to learn and compulsorily familiarize themselves with the use of computers and use of internet search engine regularly. Similarly, the university should upload more course materials promptly, produce more audio/video tapes and video compact disc for the students while radio and television should be utilised in providing both academic and administrative support for the students. Efforts should also be intensified on how to locate and attract professional organizations and individual experts in partnership for the advancement of using needed modern technology to support the university.
\end{abstract}

Key Words: Synchronous Learning, Asynchronous Learning, On-Line Support, Student Counsellors, Customised Programmes

\section{Introduction}

The National Open University of Nigeria was established to provide learning opportunities that is characterized by the separation of teacher and learner in time or place, or both time and place (Jegede 2003). It can also be regarded as a transition from the formal classroom situation, to a system where the learners pursue their studies independently and in 
their homes. The idea of establishing Open University system for Nigeria, was reflected in the National Policy on Education (NPE), which stated empathically and unambiguously that "maximum efforts will be made to enable those who can benefit from higher education (HE) to be given access to it (NPE, 1981). Every year since Nigeria got independence, the demand for places in the universities had remained unmet. Jegede (2005) in his report raised some questions: how many universities does Nigeria need if the existing universities are unable to provide places for all qualified applicants? How should the issue of access be handled? It had been suggested that to catch up with a country like Japan and meet the existing demand for admission into higher educational institution, Nigeria needs to do only two things; either it should multiply the current intake by a factor of 10 , or the country should expand the number of existing universities by a factor of 10 . According to him, it is obvious that the country would conveniently not be able to do any of the two.

Even if, the Government of Nigeria would like to do it, how will it handle the issue of facilities, infrastructure and production of academic staff? In this situation, it was suggested by educationists nation wide that one of the easiest ways of solving the problem of access is to rely on the Open University and Distance Learning, with the hope that what the conventional system cannot absorb, the Open University system will mop up. According to a student guide called "Getting to know your University (2006)", use of technology to support the learners as an initiative in the National Open University of Nigeria will complement activities of the conventional universities because it is not meant to compete with them.

The National Policy on Education (1981) is also very explicit in referring to what is known as Open and Distance Education. It stated that it is a system which encompasses education for all, education for life, lifelong education, life-wide education, adult education, mass education, media-based education, self-learning, personalized learning, part-time studies, and much more. It is this policy that forms the bedrock for establishing the National Open University of Nigeria. The National Policy on Education in Nigeria also described Open and Distance Education as the mode of teaching and learning in which learners are removed in time and space from the teachers. It therefore uses a variety of media and technologies to provide and/or improve access to good quality education for large number of learners wherever they may be (NPE, 1981).

The policy succinctly stated that, 
Federal Government shall undertake to make lifelong education the basis for the nation's education policy and that at any stage of the educational process after primary education, an individual will be able to choose between continuing his full-time studies, combining work with studies, or embarking on full-time employment without excluding the prospect of resuming studies later on. (National Policy on Education, 1981).

The above quoted policy of Federal Government of Nigeria gave birth to the Open University of Nigeria in 1983. Though the law establishing it was set aside the same year, it was reactivated in the year 2002 and functional activities started in 2003. In 2003/2004, nine thousand, seven hundred and eighty two students $(9,782)$ were registered. In 2004/2005, students were not admitted due to finance related problems. Thereafter, the financial problem was solved and 34,462 students were registered for the 2005/2006 academic session while in 2007/2008, forty seven thousand, one hundred and fifteen $(47,115)$ students registered into various academic programmes. Consequently, the entire population of students as at 2007/2008 academic session amounted to 91,359. The trend in student enrolment shows a remarkable improvement and readiness by the entire citizenry to embrace the open and distance learning. It is interesting to note that more applications are still being treated for the next admission exercise.

Jegede (2003) asserted that with the ever continuing growth in Nigeria's population, attendant escalating demand for education at all levels, the constraints of resources, the need for flexible tailor- made delivery of instruction with little disruption in National, family and individual circumstances and taking advantages of emerging ICTs in relation to Nigeria's peculiar situation, the most logical pathway is by Open and Distance Learning. From this, assertion, it is logical to conclude that the most viable alternative to face-to-face classroom system of education in Nigeria is the Open and Distance Education.

The unique features of Open and Distance Education in Nigeria were also enumerated by Jegede (2005) as follows:

- Education that is accessible to people who cannot attend regular classes due to social structural or personal situations;

- Flexibility to study at any time and place; 
- Specialized training for professional, quick material delivery, efficient academic assessments and tutor interactions;

- Learner centeredness;

- Good quality learning materials that are provided with the interest of the learners as the focus, and giving support to ensure that learners have a good chance of successful completion of their programmes; and

- Provision of learner support services.

According to Pawar (2007), learner support is a term used to subsume all interactions between institutional personnel and students (prospective and registered) which is intended to assist learners to achieve their objectives from the point of first inquiry through graduation and often for a life time. The services rendered by the learner support services are done with consideration for the learners' interest. Similarly, technology is the devise through which the university provides support to its multitude of learners.

\section{Scope}

The scope of this report included all available technological devices and strategies which the National Open University of Nigeria have procured, installed and are utilizing to provide support services to the students. On regular basis, the technological devices and strategies are equitably provided for communicating with every student either directly or through each of the study centres. The technological strategies/devices identified in the paper were,

- Radio phone-in-programme;

- Audio /Video tapes;

- Live teleconferencing

- Computer mediated learning;

- Mobile phone contact;

- Writing letters;

- Audio cassettes;

- Video CD;

- Radio broadcast;

- Online synchronous mode of interaction; and

- Online asynchronous mode of interaction.

\section{Focus}

The focus of this paper was to make the state of the art report of the technological facilities and their functional use in providing support to 
the learners who cannot attend regular classes in the National Open University of Nigeria due to social, structural or provisional situations. It also identified the ways by which various units of the University utilises technology so as to be in constant touch with students in providing academic, administrative and psychological support in order to ensure that students do not drop out of their academic pursuit but complete their studies.

\section{CASE DESCRIPTION \\ Technology Concerns}

Prior to the introduction of capital intensive technology in the National Open University of Nigeria, activities were limited to the use of mobile phone and the internet for communicating with the students particularly on issues which concerned their admission. The same technologies were also utilized for supporting the admitted students with their course registration which was done both on-line and off-line. In 2003/2004 during the first admission exercise, students who had access to the computer did the registration on-line while those who were not computer literate carried out their registration off-line. However, since the commencement of the second admission exercise, every student has been able to carry out all transactions with the university on-line, right from the application for admission to course registration, online interaction with Counsellors and Instructional Facilitators, Administrative support up to writing of On Demand Examination. Communication with students is usually done by letters, mobile phone and fax technology. Short message text was sent to the students for emergency information and reminder on issues concerning their studies, submission of Tutor Marked Assignments and date when examination would be written.

Course materials were produced in printed form but supported with instructional information recorded in audio cassettes. This was done to teach phonetics in English language to every student. The university examinations were also initially carried out in an organized way with all the students seated at the same time in the hall and in each Study Centre. However the emergence of new technology is changing the face of examination writing by students. It is now the case of an On-Demand Examination system which provides facility for students who are ready to take examination to be able to do so anytime and in any course having satisfied the condition of going through the course content and done Tutor Marked Assignments, such students can be slated to write their examination on-line. Tutor Marked Assignments are also done on-line. 


\section{Reasons for Technological Support}

Records have shown that most of the students reside in remote locations. Despite the fact that the University has created thirty-nine study centres with network of services across the country, some centres are still hundreds of kilometres away from its learners. There is therefore difficulty in interaction and transactional communication especially with students in such remote rural areas. Communication is hampered by poor road network. Consequently, the university is meeting up with this task by investing in the use of technology particularly internet for course delivery, mobile phones and other forms of communication with the students. With this, learners are able to decide on whether they want to carry a full academic course load or take their courses in bits.

\section{Technology Components}

The available technological resources that are regularly being utilized to provide support to the distance learners are:

- Radio phone-in-programme;

- Audio /Video tapes;

- Live teleconferencing;

- Computer mediated learning;

- Mobile phone contact;

- Writing letters;

- Audio cassettes;

- Video CD;

- Radio broadcast;

- Online synchronous mode of interaction; and

- Online asynchronous mode of interaction.

\section{Biometric access facility.}

The university is into collaboration with an Information Technology company called SAGEM that is based in the United States of America to provide the biometric access facility. The installation of this facility was carried out by the Excel Micro Technology representing SAGEM in Nigeria while the university technical staff worked with this firm to maintain the facility. The purpose for installing biometric access in the university was to improve the security services and regulate access to the restricted areas while at the same time, keeping record of staff movement. Other reasons for movement restriction are: to limit the movement of 
student visitors in order to help maximize the staff man-hour services being rendered to the students, encourage concentration in handling students' matters and enhance use of quality time for solving students' problems without distractions.

\section{Integrated Learning Management System. (ILMS) Technology}

ILMS as a project is a package of technologies which was introduced to the support system of the university. The purpose for introducing this type of technological initiative was to provide comprehensive platform for student and staff to gain access to on-line discussion forum through the internet. It is designed to function as an e-learning administration and record management of student information on the basis of which academic, administrative and psychological supports can be rendered to students. The university is into collaboration with an organization called Maple Test Assessment (Maple T.A.) in Canada. Initially, the University started with A-Tutor and Module which has now resulted to the adoption of the ILMS. Before the introduction of ILMS, A-Tutor was used as an open source content management system. As a facility, it was used for providing e-learning portal for students i.e. where learners carry out studies on-line either synchronously or asynchronously. It is the members of technical staff under the employment of the University that are used for managing the facility. The A-Tutor and Module also allows students to access learning content on the web during which they are taught a course in a scripted interactive session.

\section{University Bank of Events.}

This is a technological facility that is put in place for keeping Still and Motion pictures in the university. The facility is intended to create history and a repertoire for practical learning for use by students in the future.

\section{Electronic-Examination.}

This is a project and a new technology which is utilized for the management of the university examination system. The university authority has also deployed e- examination and tutor marked assignment facilities to each of the 39 study centres for immediate use by the students. The organization collaborating with the university on the project is called Maple T. A. (Maple Test and Assessment) Technology which is based in Canada. 


\section{OMATEK Laboratory}

An in-house technology training centre called OMATEK Laboratory was donated to the university by an indigenous technology firm known as OMATEK. The centre has about 60 units of very functional computer desktops. The centre which is principally utilized for local, national and international workshops is also used for short term training in computer appreciation leading to the award of certificate in computer appreciation.

\section{Mobile Communication Connectivity}

A Nigerian telecommunication company called Globacom Company also provides services to staff for internet connectivity 24 hours per day at a subsidized rate. This affords staff the opportunity to communicate with the students synchronously and asynchronously with minimum charges paid by the staff user.

\section{Techniques for Managing Technological Support Systems}

Effective management of support services for the learners in the University has been through its study centres' network which is a guiding force in rendering functional support services to the distance learners. This principle of Management was adopted in order to provide timely and improved support services to the learners. Similarly, in the University, education goes to students rather than the other way round. The institution adopts the principle of Keegan (1985) by using computer technology and computer mediated communication strategies. With this approach to teaching, it is possible to bring the classroom to every student's computer and to their chosen place of study. Ndlovu (1985) lent credence to this by stating that technology offers just-in-time delivery of complete customized programmes, so that the individual has access to learning opportunities anywhere and anytime. Most of the students are adults who are also in employment and thus may not have much time for a face-to-face kind of study. Some students are also in the purdah and cannot expose themselves. In effect, technology has therefore made things so easy for such category of learners.

\section{Learners' Access to Technology}

Over the years the characteristics of open and distance education have drastically evolved with the use of technology support services for learning in such a way that it has helped to facilitate effective communication with the students. Some of the learners are isolated or reside in remote locations where they cannot easily be reached physically 
Use of technology for supporting and developing the national open university of Nigeria Ogidan, Rotimi

but technology has made access to learning possible and functional for them. In spite of the fact that the student population is large, the university has successfully provided access to learning on-line and at students' pleasure. Data in Table 1is a distribution of the students by age and year of admission.

Table 1: Work-and-Learn Student Distribution

\begin{tabular}{|l|r|r|r|r|}
\hline & \multicolumn{1}{|l|}{ Count } & \\
\hline Age Range & $\mathbf{2 0 0 3 / 2 0 0 4}$ & $\mathbf{2 0 0 5 / 2 0 0 6}$ & $\mathbf{2 0 0 7 / 2 0 0 8}$ & Total \\
\hline $17-22$ & 51 & 1,480 & 4,398 & $\mathbf{5 , 9 2 9}$ \\
\hline $23-27$ & 572 & 4,869 & 9,952 & $\mathbf{1 5 , 3 9 3}$ \\
\hline $28-33$ & 1,933 & 7,401 & 10,495 & $\mathbf{1 9 , 8 2 9}$ \\
\hline $34-38$ & 1,920 & 6,057 & 7,107 & $\mathbf{1 5 , 0 8 4}$ \\
\hline $39-43$ & 2,055 & 6,198 & 6,827 & $\mathbf{1 5 , 0 8 0}$ \\
\hline $44-48$ & 1,773 & 5,017 & 5,160 & $\mathbf{1 1 , 9 5 0}$ \\
\hline $49-53$ & 939 & 2,568 & 2,300 & $\mathbf{5 , 8 0 7}$ \\
\hline $54-58$ & 391 & 765 & 657 & $\mathbf{1 , 8 1 3}$ \\
\hline $59-63$ & 110 & 71 & 148 & $\mathbf{3 2 9}$ \\
\hline $64-69$ & 27 & 20 & 47 & $\mathbf{9 4}$ \\
\hline Above 70 & 11 & 16 & 24 & $\mathbf{5 1}$ \\
\hline Total & $\mathbf{9 7 8 2}$ & $\mathbf{3 4 4 6 2}$ & $\mathbf{4 7 1 1 5}$ & $\mathbf{9 1 , 3 5 9}$ \\
\hline
\end{tabular}

Source: Student Registration Data Base 12th May, 2010.

Figure 1: Work and Learn Student Distribution at the University by Age and Gender

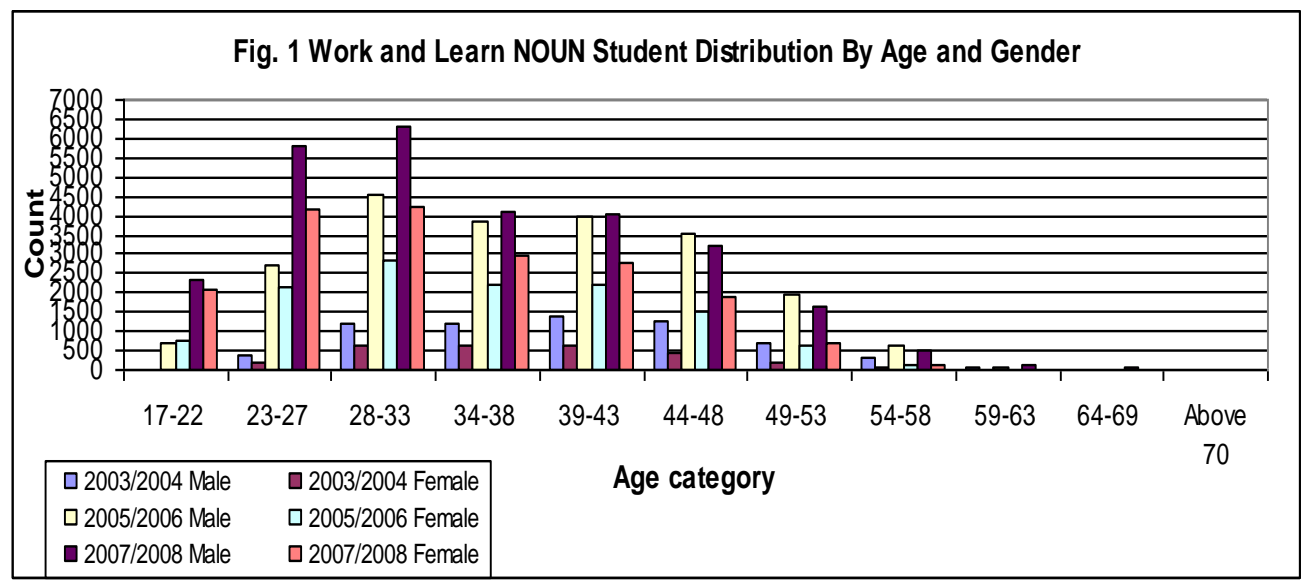

Source: Student Registration Data Base 12 th May 2010 
Table 1 and Figure 1 above show both tabular and graphical expressions of the population of the students. Figure 1 displays the students' population on the basis of age in the academic sessions of 20032004, 2005-2006 and 2007-2008. Use of technology for reaching the students becomes very necessary since they combine work with learning.

The Age -Range column on Table 1 and Figure 1 indicates that several students are combining work with studies at the same time. However, the number of the mature work-and-learn students is more than the number of the students who are relatively young and are just graduating from the secondary schools. As young as they are, they have been able to combine studies with work at the same time because of the availability of technology which is being positively utilized to improve their educational standard.

Observations show that the younger population of learners are more familiar with, and enjoy technological support facilities through the internet than the older ones. For example according to Ipaye (2008), the age distribution of 47,115 registered students for 2007/2008 in the institution shows that 4,398 of them are below 25 years of age and 9,952 are below 30 years of age. In term of employment, 5,122 of them are unemployed. However, with sufficient encouragement given to students on the use of computer and utilisation of other forms of technologies for learning, every learner would be amenable to use them regardless of age.

\section{Management of Technological Support}

\section{Directorate of Learner Support Services of the University}

This unit of the institution is one of the important organs which strives to provide support to learners right from the stage of application for admission to registration, studying and adjustment to the task of learning till such students successfully graduate and leave the institution. The directorate is headed by a Director with the assistance of study centre Managers, Student Counsellors and other support staff. The Directorate performs both administrative and academic functions through the use of mobile phone, internet and fax facilities. The Members of staff in the directorate monitor, coordinate, supervise and evaluate the performances of students through technological devices. Through similar media, vital information is disseminated as quickly as possible to the students. 


\section{Student Counsellors}

Through telephone services and internet facilities, Student Counsellors provide regular guidance and counselling services to the students. Common issues of regular concern which attract guidance and counselling intervention are: need for information on how to enrol into the university, choice of academic programmes and courses, adjustment to family life, adjustment to study life and special academic guidance which also takes place on-line. Other counselling media often employed in the institution include one to one telephone, group guidance on telephone, teleconferencing and guidance by letters with counselling services recorded in audio and video cassettes. Similar guidance services are rendered on radio broadcast, compact disc and internet chatting.

Student Counsellors also carry out the function of helping the learners to acquire appropriate study and adjustment skills in their exposure to the Open and Distance Learning mode of instructional delivery system. This is in line with the mission of the institution to provide functional, cost-effective and flexible learning which adds lifelong value to quality education for all who seek knowledge.

In addition, the Counsellors keep in touch with distance learners regularly by providing warning signals regarding difficulty in studies, thereby helping learners to take prompt remedial actions (Ipaye, 2006). Similarly, the Student Counsellors carry out the following functions:

- Communicating with the students through the mobile phone and the internet on regular basis.

- Guide distance learners in the choice and management of peer groups for the purpose of tutorial and instructional facilitation;

- Devise, develop, manage student database and constantly monitor all counselling needs of students for the purpose of providing effective guidance and counselling services;

- Provide professional consultation to students who may have difficulty with rejoining the academic world;

- Remain in constant touch with the students in order to ensure that he/she does not drop out from his/her academic pursuit;

- Help in providing preventive services by being sensitive to students' needs academically and behaviourally right from the registration stage;

- Provide guidance in the choice of suitable techniques and encourage development of sustainable study habit; 
- Provide guidance services on change of programmes, suspension of studies and deferment of admission;

- Provide guidance services on how to promote, maintain and sustain motivation;

- Help students to learn how to balance family demands with the task of pursuing their academic programme.

\section{Instructional and Tutorial Facilitators}

Instructional and tutorial facilitators are very familiar with the use of the internet technology. Through this devise, they conduct meetings and facilitate instruction at a distance and assist students in organizing professional workshops, course development and design. They conduct Tutor Marked Assignments and assist in the conduct of examinations. Other functional supports which they give to the students are:

- Assessment of skills in the art of managing essential feedback to ensure effective Open and Distance Learning amongst the students

- Monitoring of distance learners' academic progress, liaising with the external examiners, and assessors.

- Provide on-line learning support for students who have access to and prefer the web-based learning environment.

\section{Information and Communication Technology}

The Directorate of Computing and Network Services (CNS) use various facilities and strategies to provide support to the distance learners. Such services are rendered through the following arrangements and facilities.

- Provided 16 Study Centres with Plasma facilities for video conferencing and connectivity to the Nigerian Air Space Research Development Agency; and

- Equipped 6 Study Centres with computer laboratories up to 30 50 computer units each.

It also provides learners with free access to the instructional facilitators and other Open and Distance Education providers through the internet. The various Study Centres also maintain close contact with the learners.

Mealy \& Loller (2000) in a research on the use of educational communication and technology reported that it was as a result of rapid technology related developments, that courses are being delivered to 
students in various locations to serve their educational needs. Through Information and Communication Technology, distance education programs are provided to students in remote geographic locations. This initiative has led to an increasing interactivity between student and other Open and Distance Learning (ODL) personnel.

Through the internet and mobile phones, technology has assisted the learners to enjoy the services of the ICT personnel right from the period they apply for admission to registration. Students are able to communicate with the ICT experts at the headquarters of the University. They also constantly seek clarification on issues bordering on their programme and get reply immediately. The Directorate of (CNS) in the university is functionally involved in the planning of the university activities starting from admission notification, registration, conduct of examinations and announcement of results.

\section{Library Support Services}

This unit of the university provides library support services to the students because such services are regarded as important constituents of the ODL institution. The library offers facilities to students to gain access to the virtual library. In order for the students to be able to gain access to the virtual library, they have to procure the pin code of the university in their study centre. With the pin code, learners are able to access any learning material like text books, references, journals, magazines, publications including previous question papers of their choice which are in addition to the original study material that must have been provided for them course by course.

\section{Administrative Support Services}

The University created 39 study centres across the country. With this arrangement, there is a study centre in each of the thirty six states of the federation including the Federal Capital Territory, one local government Study Centre, a Study Centre each for the Army, Navy and Air force. There are also plans to create Study Centres for the Nomadic Fishermen in the southern part of the country and Nomadic Fulani in the North. The Study Centres are created to decentralise the task of providing support to the learners in their studies. There are also computer and internet facilities at the Study Centres to make study and learning activities functional so as to prevent students from dropping out of studies. Similarly, fifty two professional counsellors were employed to provide guidance services at the centres. Instructional technologies are also 
provided and used in each Study Centre. In addition to the on-line interactions, the study centres provide tutorial class rooms, science laboratories, language laboratories, students' resource centres and library facilities in order to enhance practical and effective learning activities among the students.

\section{The Directorate of Instructional Resources Development}

This directorate is responsible for all activities that concern editing and validating instructional materials in the university. It also ensures that course materials are delivered in print and on-line. After editing and validating the instructional materials, they are then uploaded for the students to download. For example, support services are provided online to supplement the print since learners can access their studies on the net any time and wherever they choose to do so. Presently, over 380 courses spanning different programmes have been uploaded to the internet ready for download by the learners. Similarly, students enjoy non web interaction through CD or DVD. These CDs, DVDs and VCDs are produced at the Kaduna campus of the university.

\section{Directorate of Media and Information}

Information and media play a major role in providing students with emergency information. The university has in its database every student's e-mail address through which students are promptly contacted. Similarly, the university has a radio station. Operations in the radio station begin at 9 am and close by $4 \mathrm{pm}$ every day. Each talk and interaction is embellished with a phone-in question and answer in areas like academic, career guidance, application of computer and network services, operation of students' financial account, sports and talks on national issues. The radio programmes are also recorded on Compact Disc for the use of any body who wants to have them.

A Television Station has also been ceded to the University particularly to complement instructional facilitation. The station renders additional service of discussing practical lessons in science and professional courses to the benefit of the distance learners who are located in different parts of the country.

\section{Challenges Facing the University}

In spite of the remarkable approach and positive impact the university is making to ensure that physical distance with students is reduced while 
transaction is strengthened with the help of technology, there are still challenges in areas such as:

- Very high cost of procuring and maintaining telephone services in Nigeria particularly for telephone interactive discussion between the learners and the university staff who are concerned with providing information service,

- Lack of internet connectivity in remote rural areas and sometimes in some study centres that are located in the city where internet service providers cannot reach regularly,

- High cost of procuring computer laptop and desktop particularly for indigent students. Such students are compelled to share with those who have or else, they may have to patronise commercial centres who will also charge them exorbitantly,

- High cost of printing down loaded course materials,

- Most distance learners in the country are not computer literate,

- Lack of efficient information and communication media facilities at the study centres,

- Most learners misconceive facilitation for face-to-face classroom teaching and they are also sceptical on how communication technology can be used for providing support in practical courses,

- Epileptic supply of electricity in Nigeria which often compels users of computers to spend more on possessing personal power generating plant.

\section{Solutions and Recommendations}

Specific recommendations that can address the issues and concerns for the improvement of the use of technology for supporting and developing the university:

- By providing corresponding audio/video tapes and video compact disc on course materials to the learners regularly;

- There should be regularly organized television and teleconferencing programmes to support the learners within stated time;

- Learner Support Services need to organise the teaching and nonteaching staff at the study centres, for training on the use of technology to the learners;

- Live teleconferencing facilities should be available in all the study Centres and be connected to the headquarters; 
- More information and communication technology experts should be employed to work particularly at the study centres;

- More course materials should be uploaded to the internet for students to download before they are ready in print form (hard copy) for distribution.

\section{Conclusion}

It is obvious that use of technology for supporting learners is the mainstay of distance education and the hub of the administrative and academic activities in the National Open University of Nigeria. It is through technology mediated support services that learners can enjoy support from the distance education providers when they interact amongst themselves without the physical distance posing any barrier. However, it is obvious that the use of any information and telecommunication equipments initiative requires learners' functional participation. High cost of computers and the epileptic supply of electricity among other challenges must therefore be surmounted so as to be able to sustain the present level of technological development and forge ahead.

\section{References}

Ipaye, B. (2007). Study guides and learning strategies in open and distance learning, Lagos: Printserve Ltd.

Jegede, O. (2003). Welcome! ... Experience a whole new world of learning. Prospectus, National Open University of Nigeria, Lagos: The Regent Ltd

Jegede, O. (2005). Induction workshop for the staff of the National Open University of Nigeria, Lagos facilitated by the Commonwealth of Learning 17-21 January, 2005.

Getting to know your University, (2006). National Open University of Nigeria publication, Lagos

Keegan, D. (1998). Foundations of distance education, London: Rutledge.

Mealy, L., and Loller, B. $(2000,28)$. E-learning: expanding the training classroom through technology, Austin, TX: Rector Duncan and Associates Press.

National Policy on Education (2004).Federal Republic of Nigeria, Abuja

Ndlovu S D (1985).Development of distance education at university level. University without walls: Some issues for consideration by developing nations. Paper presented at the 4th International conference on new concepts in higher education, by the 
Use of technology for supporting and developing the national open university of Nigeria Ogidan, Rotimi

International Council of the University Without Walls at the Royal National Hotel London.

Pawar I A. (2000). Management of students support services in the National Open University of Nigeria and BRAOU: A Comparative study. Unpublished research on fellowship, submitted to the National Open University of Nigeria, Lagos Nigeria.

Stewart D.(1995).One world many voices, Quality in open and distance learning, Journal of International Council for Open and Distance Education, Birmingham 